\title{
ANARCHISM AND RIGHTS VIOLATIONS
}

CHARLES SAYWARD

The University of

Nebraska-Lincoln

Smith is walking in the park. He is mugged by Jones, who takes his last ten dollars. Smith recognizes Jones and sets out to punish Jones and to exact compensation from him. Smith is bent on private enforcement of justice; this will involve the use of force on his part against Jones. Smith and Jones are in a territory governed by a state. I shall use 'Ipswich' to designate the particular state involved. Ipswich does not allow private enforcement of justice. Jones knows this. He also knows Smith knows that it was Jones who mugged Smith. Jones knows that Smith will come after him as a result. Jones knows there were no other eye witnesses and that it would be Jones' word against Smith's in Ipswich's courts. Thus, Jones has no fear of Ipswich's police. So he calls them, asking their protection against Smith. He gets it. The police forcibly prohibit Smith from carrying out his plans.

Did Smith have a right to punish Jones and exact compensation from him? If so, then Ipswich violated this right. We have what appears to be plausible argument for the moral illegitimacy of Ipswich.

Premise 1: Smith has a right to punish Jones and exact compensation from him as long as the punishment and compensation are not excessive ('appropriately punish Jones' for short).

Premise 2: Ipswich is an institution which has an essential function whose exercise requires it to prohibit Smith from appropriately punishing Jones. 
Premise 3: If an institution has an essential function whose exercise requires the prohibition of an action which someone has a right to do, then that institution is not morally legitimate.

Conclusion: Ipswich is not morally legitimate.

From the conclusion it does not follow immediately that no state is morally legitimate. But generalizations are obvious. One could use the same idea to prove illegitimate any state whose functions included an essential one which required the prohibition of any private enforcements of justice. Then, given the plausible premise that every state has such a function, one gets the conclusion that no state is morally legitimate.

\section{I}

One thing I want to show is that no refutation of this argument is to be obtained from Nozick's Anarchy, State and Utopia.

Consider the first two sentences of part II of that book:

The minimal state is the most extensive state that can be justified. Any state more extensive violates people's rights. ${ }^{1}$

This is the only place in the book where I find an argument against the more than minimal state. Everything else in part II is directed towards showing what is wrong with various views and arguments for the more than minimal state. Now note that the argument has a missing premise:

If a state violates people's rights, it cannot be justified.

Nozick cannot very well accept the above premise and reject premise 3 of the argument about Ipswich.

1 Robert Nozick, Anarchy, State and Utopia. New York: Basic Books, 1974, p. 149. 
Premise 2 of the argument about Ipswich is justified by the description of the Smith-Jones-Ipswich case. And, in any event, Nozick would agree that even the minimal state has the function Ipswich has-the function which precludes private enforcement of justice. So Nozick can have no quarrel with premise 2 .

That leaves premise 1 . Nozick has to reject premise 1 or else accept the conclusion. Because the argument is valid and he is committed to premises 2 and 3 . Now Nozick cannot very well accept the conclusion. Because we could easily build into the description of the case that Ipswich is a minimal state. Obvious generalizations will produce the conclusion that no minimal state can be justified, which is just the opposite of what Nozick argues in part I of his book. So he has to reject premise 1 .

It just is not clear what grounds he does have or might have for doing this. For he would certainly agree that if Ipswich did not exist and the Smith-Jones episode took place in a state of nature, then Smith would have the right to appropriately punish Jones. How does the existence of Ipswich make a difference?

We can describe ways by which Ipswich comes into existence so as to make plausible the belief that Smith would have the right in a state of nature but does not have right as a citizen of Ipswich. For example, all the (adult) in. habitants of the territory might unanimously agree to set up Ipswich. In doing this they explicitly consent to give up their right to private enforcement of justice.

This shows that the anarchist who argues that no possible state is legitimate cannot prove that conclusion because it is false. But he might still be able to prove a weaker conclusion, which will still be of great interest. The anarchist might build into the Ipswich case the contention that Ipswich came into existence many years prior to the birth of Smith, and that Smith did not enter into any agreement to give up his right to private enforcement of justice.

A standard move going back to Socrates is to say that if 
a state is not capricious or tyranical in dispensing justice and a person lives in that state for a reasonable period of time, thereby enjoying the advantages of living in that state, then that person tacitly consents to give up certain rights he would have if he were in a state of nature. So a standard response to premise 1 is to say that Smith, by living in Ipswich for a certain period of time and enjoying the advantage of doing so, tacitly has agreed to give up his right to private enforcement of justice.

I doubt if many find this move persuasive. But what is important for present purposes is that Nozick would not accept it. His discussion of the "principle of fairness" makes this clear. ${ }^{2}$

So the question remains: What possible grounds does Nozick have for rejecting premise 1 ?

Nozick considers a case very similar to the Smith-JonesIpswich case. He describes a state of nature "in which people generally satisfy moral constraints and generally act as they ought". ${ }^{3}$ Then he describes a series of steps by which a dominant protective agency comes to hold sway over a particular territory. Most inhabitants of the territory are clients of the agency. These clients agree to give up their right to private enforcement of justice against other clients in return for the protection they get from the agency. Suppose an independent (a non-client) is in the position of Smith, a client in the position of Jones, the dominant protective association in the position of Ipswich. Nozick wants to say it is morally permissible for the dominant protective association to require (force) Smith to accept its (the agency's) judicial procedures. What is his argument?

The relevant remarks occur in the section called "How may the dominant agency act?" (p. 101-108). Unfortunately, that section is not a model of clarity and precision. But here is one thing he says:

2 Ibid., p. 90-96.

3 lbid., p. 5. 
The agency may under some circumstances defend its clients against the imposition of a penalty while promptly proceeding to investigate the question of his guilt. If the agency knows that the punishing party has used a reliable procedure, it accepts its verdict of guilty, and it cannot intervene on the assumption that its client is, or well might be, innocent. If the agency deems the procedure unreliable or does not know how reliable it is, it need not presume its client guilty, and it may investigate the matter itself. If upon investigation it determines that its client is guilty, it allows him to be punished. ${ }^{4}$

We are now supposing Ipswich is the dominant protective association, Smith is the independent and Jones is the client. How do Nozick's remarks apply here? It is not even clear that Smith uses any procedure at all in determining Jones' guilt. Smith looks up and sees Jones mugging him and robbing him. Is that a procedure? If it is not a procedure, then Nozick's remarks do not apply. If it is a procedure, it is as reliable as any could be. Why does the fact that Ipswich does not know it is reliable make it permissible for it to intervene? No argument or explanation is given.

Nozick has no refutation of the anarchist argument we are examining. He cannot give up premises 2 or 3 . He cannot accept the conclusion. So he has to reject premise 1 . But he gives no convincing argument that premise 1 is false.

\section{II}

The place to attack the anarchist argument is at premise 1 or premise 3. And of these two, premise 1 seems the least vulnerable.

For the defender of Ipswich has these options with regard to premise 1. (i) $\mathrm{He}$ can deny that Smith would have a right to appropriately punish Jones even if the mugging had

4 Ibid., p. 104. 
taken place in a state of nature. (ii) He can grant that Smith would have this right; he then has to explain how being under the jurisdiction of a state means he does not have this right. Option (i) is implausible on its face. So is option (ii) if we build into the description of the case the stipulation that Smith nowhere explicitly enters into an agreement to give up a right to private enforcement of justice.

So the place to attack the argument is at premise 3 . Here again is what it says:

Premise 3: If an institution has an essential function whose exercise requires the violation of someone's rights, that institution is morally illegitimate.

The content of this proposition needs comment. It does not say that an institution is illegitimate if it happens to violate someone's rights. A particular state may be run at a particular time by fools who are continually violating citizen's rights because of small brains and what-not. That is not a reason for condemning the institution; although it is a reason for changing governments.

Premise 3 says something more plausible: Suppose an institution has a function which cannot be properly exercised without violating peoples' rights. That would be a reason for taking that function away from the institution, not for dismantling the institution. But now further suppose that function is an essential function of the institution. Without that function the institution would not exist. If the rights violations were required by the exercise of that function, the institution itself would be at fault (rotten to the core). The institution in that case should be dismantled. It would be morally illegitimate. This is what premise 3 says.

III

One plausible and natural line of attack of premise 3 proceeds as follows: We are assuming that Ipswich is not ca- 
pricious in dispensing justice, and treats its citizens in a reasonable way. An essential function of Ipswich is to reserve for itself the enforcement of justice. Suppose there were no institution having this function. Then the risk of wholescale rights violations would be maximized. If Ipswich did not exist and the territory involved were not under the jurisdiction of any state, then, unless the vast majority of persons in the territory moved to state controlled areas, the total weighted amount of the violations of rights in that territory would be increased. Generally if there were no institution with the function of reserving for itself the enforcement of justice, the total weighted amount of rights violations would increase. The price of minimizing total rights violations is to violate such rights as Smith's right to appropriately punish Jones. It is unfortunate that this is required, but the price is not too high. Hence premise 3 is false.

This line of attack and variants occur invariably in conversations about premise 3 . It seems to be a very natural move. Is it a good argument?

Consider one key premise:

(U) If there were no institution that reserved for itself the enforcement of justice, then the total weighted amount of rights violations would be increased.

I find those who advance arguments like the one we are now considering to generally underestimate the difficulties involved in justifying such counterfactural assertions as (U). Some counterfactuals can be justified. We know that 'If there were no oxygen in this room for a period of two hours and Bill were locked in this room for that time, Bill would be dead' is true because of highly confirmed generalizations we can make about the human body and its need for oxygen. But there are no such generalizations we can use to justify the counterfactual premise of the utilitarian-type argument we are considering.

A response to this counter to $(\mathrm{U})$ is this. There seem to 
be many counterfactuals that can be justified without the use of a highly confirmed generalization. For example, I am very myopic; I cannot get along without glasses. Using such facts as these could not one justify such a counterfactual as

If Charles Sayward had broken his glasses yesterday, he would have taken steps shortly afterwards to get them replaced.

without having to make use of a well-confirmed generalization? Similarly, a defender of (U) might seek to justify it by citing various historical instances.

Of course, a utilitarian anarchist might seek to justify a contrary counterfactual

$\left(U^{\prime}\right)$ If there were no institution that reserved for itself the enforcement of justice, then the total weighted amount of rights violations would be decreased

in a similar way. Does the evidence support (U) more than it does $\left(\mathrm{U}^{\prime}\right)$ ? A resolution of this issue is bound to be complicated and messy. And none is currently available. But until such a resolution can be given in favor of (U), the utilitarian-type argument against premise 3 has to be regarded as being based upon an unjustified premise.

IV

A more plausible case against premise 3 seeks to undercut the view that it is never permissible to violate a right. For if it is sometimes permissible to violate a right, then it may well be permissible for Ipswich to violate Smith's right to appropriately punish Jones. At least the burden of proof would be on a defender of premise 3 . That person would have to explain why it is not permissible for Ipswich to violate Smith's right, while it is permissible to violate rights 
in these other uses. If the defender of premise 3 cannot do this then the whole argument rests upon an unwarranted assertion.

Now say that A has a friend B who has just lost his wife and child in a car accident. The idea of living without them is revolting to him. He decides to kill himself. He is despondent but not insane. He calmly comes to the conclusion that he just does not want to live. A forcibly prevents B from killing himself. A puts B in a straightjacket, and keeps him there for as long as he thinks is necessary. Would A have done anything wrong in so acting? It is hard to see what A would have done wrong. And, yet, did not A's friend have a right to take his own life? $B$ is a rational agent. He comes to the conclusion that life is no longer tolerable. By taking his own life he does not violate anyone else's rights. It is certainly plausible to say that in this case (i) A's action violated his friend's right and (ii) A's action was permissible.

Take another case. Every person has a right not to be used or sacrificed for some end without his consent. In many cases, violations of this right are evil acts. But not in all cases. Certainly not in all conceivable cases. For example, suppose A's friend B has possession of a formula to deactivate a nuclear device. If the device goes off, mankind will cease to exist. It is set to go off in twenty-four hours. Nobody else knows the formula. B will not reveal it. He is so embittered about what happened to his family that he has no inclination to save mankind. $\mathrm{A}$ has in his possession a sophisticated torture device. It is within his power to strap $B$ onto the device. A can then push a button. B will experience such intense pain that his information has to come out. A does this to him. In so doing, A violated B's right because A sacrificed him for some end he did not consent to. Surely A did what he ought to have done, however.

These cases, and countless others, illustrate the same point: It just is not obvious that it is always wrong to violate a right, even a natural right. Sometimes it is permis- 
sible to do this; sometimes it is even obligatory. How, then, can there be any warrant for asserting premise 3 ? Let us grant that Smith has a right to appropriately punish Jones. Then Ipswich does violate this right. And this violation results from a correct exercise of an essential function of Ipswich, a function without which Ipswich would not be a state. Why does it follow that Ipswich is illegitimate? It does not even follow that Ipswich did anything wrong in violating Smith's right.

In response to this case against premise $3 \mathrm{I}$ point out relevant differences between Ipswich's violation of Smith's right and the putative rights violations in the other two cases.

Take the suicide case. Some might raise doubts about whether $B$ does have a right to take his own life. But, in view of the fact that $B$ is a rational agent and that his decision to take his own life does not violate anyone else's right, the claim that $B$ does have this right is certainly reasonable and not one I would wish to challenge. Now what backs up the intuition that A's action (forcibly preventing $B$ from committing suicide) was permissible? I think it is that B's life could be saved only by violating B's right. Generally, where there is a clash between saving a human life and observing a particular right, it is more important to do the former than the latter.

This is more manifest in the second case. B arguably has the right not to divulge his information. We feel it is monstrous of him not to want to save mankind from destruction, but I do not see what right of anyone $B$ is violating by refusing to divulge his information. So $A$, by forcing $B$ to do this, violated B's right to remain silent. Here we are certain $\mathrm{A}$ did the right thing. Again the underlying reason is that if there should ever be a clash between saving mankind from destruction and observing someone's right, it is by all means more important to do the former than the latter.

So, in each case there is some identifiable goal $G$ such that it is more important to achieve $\mathrm{G}$ than to observe someone's right should there be a clash between the two. 
Now what is the goal which justifies Ipswich's violation of Smith's right to punish Jones? Of course, imaginary Ipswich is not what concerns us. What concerns us is that function Ipswich shares with every state: reserving for itself the enforcement of justice over a reasonably large area for a reasonable long period of time. The exercise of this function inevitably leads to rights violations of the sort described in the Ipswich-Smith-Jones case. So if we are seeking to justify any institution which has this as an essential function along the same lines taken in our suicide case and our torture case, we need to identify some goal $G$ such that

(X) If there were no institution reserving for itself the enforcement of justice, $G$ could not be achieved

is warrantedly assertable.

One plausible candidate is decreasing the total weighted amount of rights violations. Then (X) becomes (U). Most people (myself included) suspect (U) is true. But suspecting (U) to be true does not make it warrantedly assertable. The same justification problem posed for (U) holds for any other goal one might plausibly set for $\mathrm{G}$ in (X). So I conclude that the two cases set out in this section really provide no basis for denying premise 3 .

\section{V}

The argument which concludes that Ipswich is not morally legitimate is easily generalizable: if that argument is sound then we can also prove no state is morally legitimate. Now the argument about Ipswich is valid; more important, its three premises are each defensible. The most sustained recent attempt to justify the state occurs in part of Nozick's Anarchy, State and Utopia. We have seen that what Nozick says there provides no basis for rejecting any of these premises. Neither do standard utilitarian-type moves. 
The justification of the existence of the state should precede the justification of any particular organization of the state. I regard the main contribution of this paper to be a clear formulation of the problem of justifying the state: Which of the premises about Ipswich is false and why? 